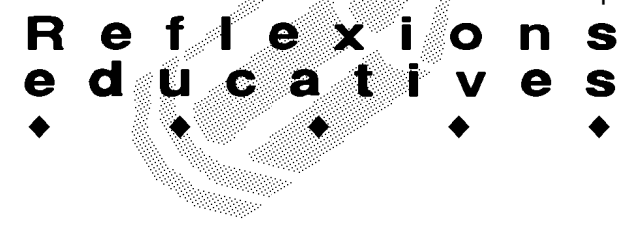

\title{
APRENDRE COOPERANT PER APRENDRE A COOPERAR
}

\author{
Joan A. Traver Martí. Àrea de Teoria i Història de l'Educació. Universitat Jaume I. Castelló
}

Vivim moments difícils, temps d'estranyes solidaritats. Malgrat el que ens ha plogut -i encara ens plou-, pensar la cooperació a l'escola resulta un fet prou atípic. Ens trobem immersos en una societat massa egoista i competitiva, on no abunden les conductes desinteressades i solidàries. Els efectes de la globalització econòmica i els grans fluxos migratoris han comportat també altres globalitzacions no desitjades. Cercant un món més segur, el primer món ha sembrat desconfiança cap als altres; cercant més beneficis de mercat, més competitivitat, ha generat més desigualtat social; enlairant a les ones mediàtiques les bonances de la vida al primer món, ha propiciat una fugida desesperada cap a l'abisme, que malauradament hem fet que ens separe. Rebuig $i$ xoc cultural, intolerància i xenofòbia, desigualtat i fracàs escolar, exclusió educativa i social, són entre d'altres les globalitzacions silenciades que ens recorden que el futur és de tots $i$ totes o no ho serà. Sense els "altres" simplement no tenim futur. L'acció, la relació solidària, sembla un dels majors dèficits que arrossega la nostra societat.

I davant d'aquest fet tan macro, que sembla que se'ns escapa de les mans, alguna cosa caldrà fer. Situats davant d'aquesta tessitura, pels moviments antiglobalització la dinàmica a seguir és prou clara: pensar globalment, actuar localment i valorar críticament. Aquests, tot i no ser els millors moments per a la lírica, haurien de ser moments per al rearmament moral i intel-lectual que ens allunye definitivament de la cultura de la queixa. Com ja assenyalava Freire (1997), davant la cultura de la queixa, la cultura de l'acció i la transformació. Hem de recuperar la capacitat d'actuar: "La capacitat d'actuar és el que fa de la vida quelcom de valuós [...] Viure sense actuar és renunciar a la pròpia humanitat" (LARRAURI, 2001).

I en aquest camí de les transformacions necessàries el professorat tenim alguna cosa a dir. La nostra tasca, segons Morin (2001), és una missió de salvació pública: "El caràcter professional de l'ensenyança condueix a reduir l'educador a expert. El caràcter funcional de l'ensenyança condueix a reduir el professor a funcionari. L'ensenyança ha de tornar a ser no sols una funció, una especialització, una professió, sinó una tasca de salvació pública: una missió". L'ensenyança tradicional no sols no ofereix solucions a aquests problemes, sinó que, en part, n'és coresponsable. Com s'assenyala al Manifest de la Red IRES (Investigació i Renovació Escolar, document disponible en www.redires.net): "No és veritat que a l'escola espanyola actual predomine un model d'ensenyament diferent al tradicional". Davant d'aquesta problemàtica caldrà replantejar-se, entre moltes altres qüestions, quina és i a què respon l'eficàcia dels mètodes pedagògics emprats, quins aprenentatges fomenta $i$ quins silencia. Les polítiques educatives de nou manteniment, basades en l'adoració de la cultura de la culpa i la queixa i de l'individualisme pedagògic, que estan a la base d'una concepció transmissiva del fet educatiu, s'han mostrat del tot insuficients per transformar aquesta realitat. Enfront dels discursos obsessionats en l'encabotament curricular, és hora ja d'aprofundir i apostar per les propostes de l'aprenentatge innovador. Propostes basades en una visió plural del fet educatiu, en el valor del diàleg i el pensament crític, en la cultura de la transformació i la cooperació docent i comunitària. Davant d'aquesta realitat educativa, tan poc donada a l'esperança en la construcció d'un projecte d'humanització més just i solidari, l'aprenentatge cooperatiu es mostra com una de les alternatives raonables que poden aportar algun dels ingredients necessaris per avançar en la seua transformació.

\section{Quan el treball en grup no és prou: d'una condició necessària però no suficient}

Una de les primeres diferenciacions a establir, per poder centrar el que entenem per aprenentatge cooperatiu, és, tal com apunta Ovejero (1990), la derivada d'aplicar el terme cooperació a les estratègies d'ensenyançaaprenentatge o bé a la identificació del tipus de gestió de l'aula. En aquest segon cas, no em refereix a la utilització de tècniques d'aprenentatge cooperatiu, sinó més prompte a la participació dels alumnes en l'organització i estructuració de la vida de l'aula i del centre des d'un punt de vista cooperatiu: gestió a realitzar de forma col-laborativa i coresponsable entre professorat i alumnat, 0 entre professorat, pares/mares i alumnat. És el que autors com Henz (1967) o Bragulat (1987) defineixen com a cooperació responsable o sistemes cooperatius d'ensenyança.

Ara bé, tot i la importància que el treball en grup sembla tenir per a aquesta empresa, hem de deixar clar que no qualsevol tipus d'interacció social presenta la potencialitat educativa de què estem parlant. És interessant recordar que no és el mateix treballar en grup-sense més- 


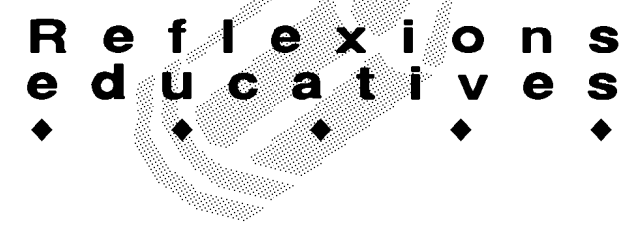

que treballar en grups cooperatius. Tradicionalment s'ha associat l'aprenentatge cooperatiu amb l'aprenentatge en grup a l'aula. S'associaven -i en molts àmbits encara es continuen associant- les tècniques de dinàmica de grups amb les d'aprenentatge cooperatiu, amb les quals s'esperava aconseguir resultats educatius en l'alumnat que anaven més enllà del que les dinàmiques grupals per si soles poden oferir. Pel fet de distribuir les propostes d'activitats en l'aula per grups de treball no podem deduir que això redundarà irremeiablement a promoure conductes més col-laboratives i solidàries entre els participants. Des d'aquesta concepció del treball en grup, la preocupació en la definició de l'equip va sobretot dirigida a trobar aquells criteris que ens orienten sobre quines són les característiques de composició del grup que facilitaran la seua implementació: edat, nombre de membres, homogeneïtat/heterogeneïtat, etc. Utilitzem, d'aquesta manera, el terme equip com a oposat a individu, des d'un punt de vista quantitatiu, creient que la principal diferència entre el treball individual i el grupal radica essencialment en aquest fet. La distribució de l'aula en xicotets grups de treball posa els alumnes en situació de relacionarse entre ells, però la naturalesa d'aquesta relació variarà en funció que, a més, estructurem tant el grup com l'activitat a realitzar i els seus propòsits de forma cooperativa.

Una de les contradiccions que majorment trobem en la utilització del treball en equip, i que té l'origen en les raons ací apuntades, és aquella que, després d'organitzar la classe en grups de treball, continua mantenint propostes de treball per a cada un dels grups, basades en els plantejaments de l'ensenyança-aprenentatge individual. D'aquesta manera, l'única cosa que es pot donar entre l'alumnat és, o bé un repartiment del treball a realitzar entre ells i elles -constituint-se la producció grupal com una simple addició de cada una de les parts-, 0 bé que cada membre d'un grup d'aprenentatge treballe el mateix que els altres i aconsegueixca el mateix nivell de rendiment. Són molt més adequats per a aquestes finalitats els agrupaments homogenis respecte a la capacitat d'aprenentatge. La interacció entre iguals queda devaluada enfront del paper del mestre o la mestra, com a referència quasi exclusiva, en la construcció del coneixement que cadascun dels i les alumnes realitza. Les funcions del docent segueixen basades en el seguiment i control individualitzat de les activitats de l'alumnat i en la necessitat d'individualitzar les seues produccions per estimular la seua creativitat i implicació en el treball; però sense referències a un marc de coordinació interindividual i a la comprensió conjunta dins del xicotet grup.

Una altra idea prou estesa dins de l'àmbit pedagògic que poc favor ha fet a la difusió de les tècniques d'apre- nentatge cooperatiu és la creença que les relacions que es donen en les activitats d'aprenentatge entre l'alumnat dins de l'aula tenen una repercussió més prompte negativa per als resultats de les dites activitats (JOHNSON, 1981; OVEJERO, 1988). A causa d'això, tradicionalment s'ha considerat que l'única relació desitjable per a l'èxit dels objectius educatius és la interacció professoralumne, intentant reduir al mínim les relacions que es donen entre l'alumnat. No és estrany trobar-nos en les aules amb organitzacions de l'espai, del temps i dels recursos materials i personals que afavoreixen aquesta consideració. Així ocorre, per exemple, en la típica distribució d'alumnes per files d'un, on cada alumne ocupa el seu pupitre i disposa de poques possibilitats físiques per posar-se en contacte amb altres companys; amb la taula del professorat situada al front, de forma estratègica, controlant-ho tot. $\mathrm{O}$, també, en les normes $\mathrm{i}$ hàbits de treball que condueixen que cada alumne realitze les seues activitats, aillat de la resta: observar silenci absolut, excepte quan es dirigeix al professorat, demanar permís per a realitzar qualsevol desplaçament, no alçar-se de la cadira si no ho requereix el mestre o la mestra, contestar només quan se li pregunte, etc. Des d'aquest punt de vista, el docent ha de realitzar un considerable esforç personal per poder mantenir mínimament aquestes condicions, amb la consegüent fatiga laboral, acumulació d'estrès i frustració professional, en cas de no poder aconseguir-ho, dedicant moltes més energies a funcions de control que a les pròpiament educatives. El clima de classe així creat, amb aquesta selecció i organització dels materials i de les propostes de treball, amb aquesta distribució de l'espai i aquestes normes de comportament, és tributari d'una concepció pedagògica que veu el professorat com a única font de saber, que tan sols necessita dotar-se d'una bona estructura de control sobre l'alumnat per poder avançar pel tortuós camí de l'ensenyança (COLL i COLOMINA, 1991). Amb això, estem potenciant tant l'individualisme com la competitivitat entre els nostres alumnes, la submissió i la dependència, la falta d'espontaneïtat i de creativitat.

Sintetitzant, podem concretar les principals diferències entre el treball en grup i l'aprenentatge cooperatiu en els aspectes següents:

1. Les propostes d'aprenentatge en grups cooperatius es basen en la interdependència positiva entre els membres del grup. L'estructuració dels objectius i de les finalitats de l'aprenentatge ha de realitzar-se de tal forma que cada alumne o alumna necessite interessar-se tant en el rendiment de tots els seus companys i companyes com en el propi, característica que no es dóna en les pro- 


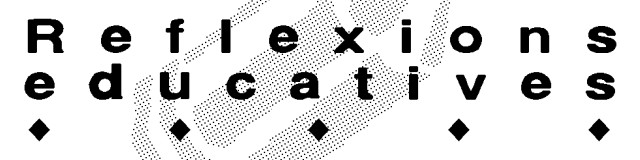

postes tradicionals de treball en equip.

2. En els grups d'aprenentatge cooperatiu existeix tant responsabilitat individual com coresponsabilitat entre els membres del grup respecte al treball a realitzar. Individualment i col-lectivament, cadascun dels participants d'un grup de treball rep retroalimentació relativa al propi progrés, al dels altres i al de l'equip, de forma tal que el grup es troba en condicions d'autoadministrar-se ajudes pedagògiques entre els seus components.

3. La composició dels grups de treball cooperatius és heterogènia, en contraposició a la del treball en equip, on normalment sol donar-se una composició homogènia.

4. En el treball en equip, normalment sol plantejarse una delegació de l'autoritat docent en el membre més capacitat del grup, a qui s'atribueix el lideratge. Enfront d'això, en els grups de treball cooperatiu sol buscar-se un lideratge compartit 0 democràtic entre tots els seus membres.

5. Les tècniques, estratègies $i$ habilitats necessàries per desenvolupar el treball en grups d'aprenentatge cooperatiu són objecte explícit d'intervenció educativa. Són ensenyats directament pel professorat prèviament i/o durant el mateix procés d'implementació en l'aula. Aquesta condició no sol donarse en el treball en equips, ja que en aquest segon cas es pressuposa que les habilitats socials i les capacitats que l'alumnat necessita per treballar en grup és un prerequisit que han de posseir abans de prendre la decisió d'utilitzar dinàmiques grupals. En el cas que aquestes fallen se sol abandonar aquest tipus de plantejaments i es torna novament a propostes de tall individualista.

\section{La cooperació al descobert: la importància de sentir- nos necessaris $i$ interdependents}

Un factor clau en l'organització social de les activitats d'aprenentatge en l'aula és la interdependència que existeix entre els participants en una situació d'aprenentatge i les metes o objectius que persegueixen. Com assenyalen autors com Johnson i Johnson (1987) o García López (1996), en les situacions escolars les relacions amb els companys i companyes poden ser estructurades de forma tal que possibiliten una interdependència positiva entre les persones a través de l'aprenentatge

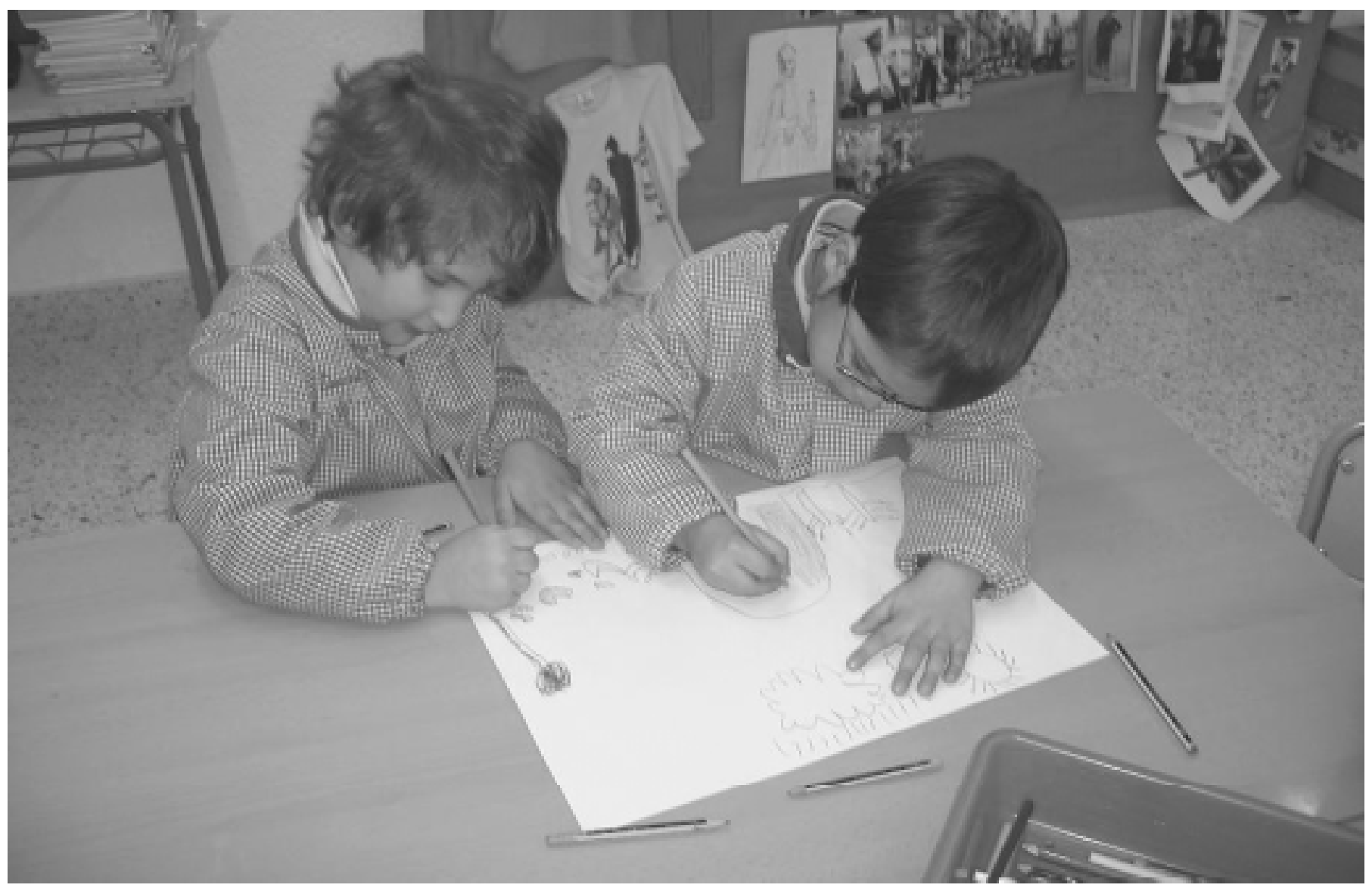




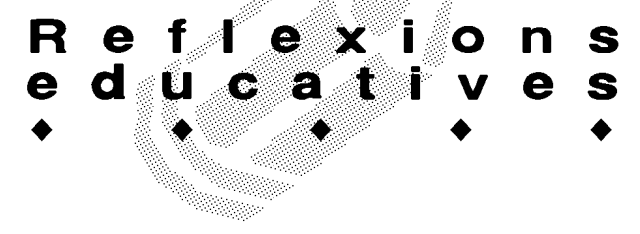

cooperatiu, afavorint l'adquisició dels aprenentatges per part de l'alumnat des de la potencialitat educativa que entranya la interacció social. Però, endinsant-nos un poc més en l'anàlisi de l'aprenentatge cooperatiu, resultaria excessivament simplista -i quasi mal intencionat- arribar a pensar que és la simple interacció entre l'alumnat la que produeix els efectes mencionats. Allò característic de les tècniques d'aprenentatge cooperatiu no és, contràriament a la creença tradicional respecte a les tècniques de treball en grup, que els alumnes treballen junts, sinó que ho facen de mode cooperatiu, és a dir, de manera que els objectius de les persones participants es troben vinculats de tal forma que cada una només puga aconseguir els seus objectius $\mathrm{si}$, i només si, les altres aconsegueixen els propis (RUÉ, 1989).

Segons Melero i Fernández (1995), per esbrinar les causes dels resultats positius obtinguts per les estratègies d'aprenentatge cooperatiu i els mecanismes implicats, és necessari realitzar una incursió a l'interior mateix de la interacció entre iguals, passant dels estudis centrats en el producte (connexió entrades-eixides) a l'anàlisi detallada del procés interactiu (la seua naturalesa o qualitat). La naturalesa de la interacció ens serveix per dilucidar què anomenem aprenentatge cooperatiu $\mathrm{i}$ què treball en grup. En aquest sentit, autors com Echeita (1995) o Coll i altres (1995) assenyalen que no és possible comprendre els processos específics d'aprenentatge que es generen en l'alumnat en el transcurs de les interaccions cooperatives sense atendre a una consideració psicosocial d'aquests ni al marge dels processos d'ensenyança-mecanismes d'influència educativa-que el professorat implementa en classe per provocar l'aprenentatge del seu alumnat.

Els mecanismes d'influència docent són els responsables, en gran part, del tipus d'interacció que s'estableix entre l'alumnat quan realitza activitats d'aprenentatge a classe. Des del punt de vista de la interdependència que cal establir entre l'alumnat, el professorat, quan dissenya les propostes educatives a implementar a classe, pren decisions -reflexivament o irreflexivament- sobre els elements o estructures bàsiques d'organització de les tasques o activitats d'aprenentatge, també anomenades estructures d'aprenentatge. El rendiment escolar de l'alumnat, el seu autoconcepte o les expectatives d'èxit o fracàs en les activitats escolars estan mediatitzades per processos cognitius, afectius i motivacionals, que varien en funció de com el professorat haja estructurat les tasques d'aprenentatge (ECHEITA i MARTÍN, 1991). Per estructures d'aprenentatge entenem el conjunt d'accions i decisions que els docents prenen respecte a distintes dimensions del fet educatiu, com per exemple el tipus d'activitats a realitzar per l'alumnat, el grau d'autonomia que tenen el professorat i l'alumnat, la modalitat de reconeixement del treball o la forma d'aconseguir els objectius (ECHEITA, 1995). A partir dels treballs $\mathrm{i}$ de les anàlisis realitzades sobre les estructures d'aprenentatge (SLAVIN, 1980; ECHEITA i MARTíN, 1991; MELERO i FERNÁNDEZ, 1995; ECHEITA, 1995), podem identificar quatre estructures d'organització de les propostes educatives:

- Estructura de l'activitat: tipus de treball que realitzaran els i les alumnes. L'estructura de l'activitat pot variar en funció del tipus de tasques que realitza l'alumnat a classe (reproductives, transformadores, d'indagació i recerca, memorístiques, etc.), del tipus d'agrupament (treball individual, per parelles o grups, fixes, variables, etc.) i del grau d'especialització de les activitats.

- Estructura de la meta: quines finalitats i objectius es persegueixen individualment i/o grupalment. L'estructura de la meta té a veure amb la forma en què els subjectes perceben i poden aconseguir els seus objectius. Es mou entre tres possibilitats bàsiques: individual, competitiva o col-laborativa.

- Estructura de la recompensa: de quina forma es valorarà i es reconeixerà/premiarà l'activitat realitzada. En l'ensenyament se sol associar aquesta estructura amb l'avaluació dels aprenentatges de l'alumnat. Quan l'estructura de la recompensa fa referència exclusivament a l'ús dels incentius, es refereix a la manera peculiar de distribuir reforços externs de distinta classe entre els participants del grup.

- Estructura de l'autoritat: qui controla i decideix allò que s'ha de fer, allò que es pot o no es pot fer. L'estructura de l'autoritat es refereix al grau d'autonomia que els i les alumnes tenen, a l'hora de decidir i organitzar les activitats i els continguts escolars, en conseqüència, al grau de control exercit pels estudiants, pel professorat o per altres adults.

L'aprenentatge cooperatiu és primàriament un canvi en l'estructura de la meta, fomentant la interdependència dels objectius entre els membres del grup, però també implica canvis en els altres elements que componen l'estructura d'aprenentatge. En una organització de l'aprenentatge de forma cooperativa cada alumne o alumna participant sap que el seu èxit personal ajuda els seus companys i companyes a aconseguir el seu. Els resultats que persegueix cada membre del grup són beneficiosos per a tots. Entenent sistèmicament les relacions entre aquests tres tipus d'estructures, podem aventurar que els canvis produïts en l'estructura de la meta també 


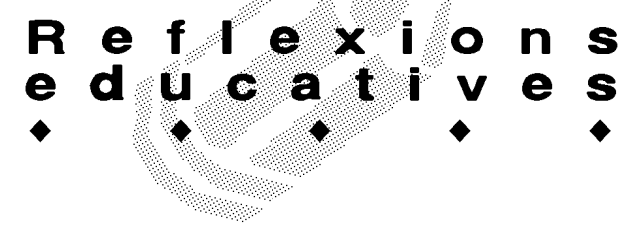

produiran canvis en les altres dos estructures. L'estructura de l'activitat ha d'evolucionar des d'una organització de l'activitat primàriament individual fins a una altra estructura caracteritzada per la interacció dels alumnes en xicotets grups, que en conseqüència hauran de gaudir de més autonomia decisòria respecte al seu treballi afectaran, per tant, l'estructura de l'autoritat.

\section{Cooperar en l'aula: una manera eficaç i valuosa d'apren- dre, de conviure i de treballar}

L'aprenentatge cooperatiu, tal com planteja Echeita (1995), consisteix en alguna cosa més que la simple disposició de les classes en grups. És una organització intencional de l'estructura d'aprenentatge que persegueix objectius educatius distints i complementaris, que van des de la facilitació dels aprenentatges de l'alumnat i l'intent d'augmentar el seu rendiment escolar, fins a ensenyar estratègies i habilitats de cooperació en l'aula i amb els companys i companyes, passant per fomentar actituds de respecte i colllaboració. Treballant de forma cooperativa l'alumnat aprèn amb molta més eficàcia i sentit els continguts escolars, i aprèn al mateix temps a col-laborar amb els altres, a compartir projectes i a conviure desenvolupant el sentiment de pertinença al grup. D'aquesta manera, tal com diu Pujolàs (2004), podem aconseguir que puguen aprendre junts en una mateixa aula alumnes diferents.

Ara bé, aquestes qüestions ni es transmeten per via genètica ni es donen per ciència difusa. Aquests coneixements s'aconsegueixen gràcies a un altre tipus de transmissió genuïnament humana: l'educació. I perquè pugam gaudir de les experiències d'aprenentatge que ens permetran construir-los, com també assenyala Pujolàs (2008), fan falta tres coses: en primer lloc, que existeixca un grup amb el qual pugam interaccionar de forma cooperativa (creació i cohesió de grup); en segon lloc, que els companys i companyes de grup sapigam comportar-nos solidàriament (aprendre a cooperar), i en tercer lloc, que els contextos d'ensenyament i aprenentatge estiguen organitzats de forma tal que propicien la construcció compartida dels coneixements entre els membres $\mathrm{del} / \mathrm{dels}$ grup/s (cooperar per aprendre).

Si passem a analitzar cadascun d'aquests tres àmbits d'intervenció, tenim:

a) Creació i cohesió de grup. Resulta del tot impossible aprendre de manera cooperativa si no tenim un grup amb el qual fer-ho possible. Hem de saber que un grup d'aprenentatge no naix per art d'encantament, tot $\mathrm{i}$ que els seus membres hagen estat "tocats" pel dit cabal del professorat. Un grup d'aprenentatge, com qualsevol grup humà, necessita fer i que passen certes coses per tal que a si mateix es veja com a grup. Necessita generar cohesió entre els seus membres i construir identitat col-lectiva. I això no es pot fer sense els altres ni sense compartir els somnis, l'amistat, l'alegria i fins i tot els conceptes, els sabers, les experiències o la música que fa sentir-nos radicalment grup. Per això és tan i tan important, per exemple, cercar un nom que ens identifique. Però, tot $\mathrm{i}$ sentir-nos reconeguts amb aquest nom necessitem molt més. En primer lloc, necessitem conèixer-nos i apreciar-nos, reconèixer l'altre 0 l'altra com una persona amb capacitats i potencialitats pròpies. Però, a més, perd del tot sentit la nostra existència com a grup si no tenim projectes que compartir, que ens facen millorar la nostra potència de vida $i$ ens permetin somniar junts. Sols quan has visitat una escola que somnia entens la força d'aquesta activitat no lucrativa. Somniar i riure han de ser notes d'una mateixa melodia. Com deia Hanna Arendt, sembla evident que compartir l'alegria és absolutament superior a compartir el patiment. A les terres valencianes diem que un claustre de professorat al qual no li agrade l'arròs té poques coses a fer junts. I sense fer coses junts, sense compartir experiències que ens fan compartir conceptes i sabers, que difícil resulta que un grup creixca com a tal. Per tant, resulta necessari que el professorat durant el curs organitze i propicie experiències que permeten al grup classe i la resta de xicotets grups de treball créixer en cohesió. Com el foc, el sentiment de comunitat no en té prou, de ser encès: cal anar anant alimentantlo sempre.

b) Aprendre a cooperar. En qüestions de convivència hem de reconèixer que arrosseguem una gran malaptesa col-lectiva. Hem de ser sabedors, com deia abans, que l'educació constitueix l'única via de transmissió de l'aprenentatge cooperatiu. Com de difícil ens resulta dialogar: treballar des del dissenys, exercir la crítica i arribar a acords. Si ens parem a mirar a casa, al treball o a l'escola, quins pocs exemples trobem de com s'ha de fer. La nostra no podem dir que és una tradició dialogant, ni col-laborativa ni solidària. En aquest sentit, defineisc l'acció solidària com una "relació fraternal de mútua ajuda, que vincula els membres d'una comunitat, col-lectivitat o grup social en el sentiment de pertinença a ell i en la consciència d'uns interessos comuns i compartits"' (TRAVER, 2005). Tenir més habilitat en les relacions que mantenim amb els altres, aprendre a construir en companyia, a comprometre'ns i a saber exigir als altres en 


\section{$\begin{array}{lllll}R \text { eftce } & \text { i o n s } \\ \text { e d u c a t i v e s } & \end{array}$}

temps i forma, a dir les coses bé, a escoltar, demanar i donar ajuda són, entre altres, els aprenentatges que constitueixen la riquesa de la cooperació. No s'hi val a aguantar i aguantar una relació que ens xupla com una sangonera sense comprometre's amb les coses que com a grup hem quedat i no dir-li res perquè ens sap greu o no ens hi atrevim. Carregar-se de raons per perdre la raó mai no ha estat un comportament dignament humanitzador. Aprendre a cooperar és aprendre a compartir, a conviure i a donar-li una dimensió socialment justa a la nostra existència. A Pallarés i altres (2007) presentem una proposta per treballar les habilitats cooperatives amb l'estudiantat universitari de la Universitat Jaume I, que també hem emprat de manera satisfactòria en l'ensenyament no universitari. Si com a docents no dediquen un temps, uns espais i uns recursos educatius a realitzar aquests aprenentatges, no podem pretendre que els grups de treball siguen eficaços quan pretenen col-laborar en les activitats educa- tives. I en aquesta empresa, si no ens hi va la vida sí que ens hi va, en un sentit ètic, "la bona vida".

c) Cooperar per aprendre. Quan parlem de cooperar per aprendre, quan parlem que han d'aprendre junts alumnes diferents, fem referència que un grup cooperatiu ha de respondre a una filosofia inclusiva. Tots i totes hem de poder formar part del grup, i tots i totes hem de tenir més i millors oportunitats d'aprenentatge pel fet de poder compartir la nostra experiència educativa amb els nostres iguals. Allò que genera exclusió en els processos educatius són els mateixos contextos d'aprenentatge. En funció de la seua planificació, de com s'organitzen les diferents estructures d'aprenentatge (meta, recompensa, activitat i autoritat), augmenta o disminueix la seua potencialitat inclusora. En aquests darrers anys assistim a un increment notable de la investigació i de la literatura pedagògica dedicada a l'estudi i a l'anàlisi de l'aprenentatge entre iguals.

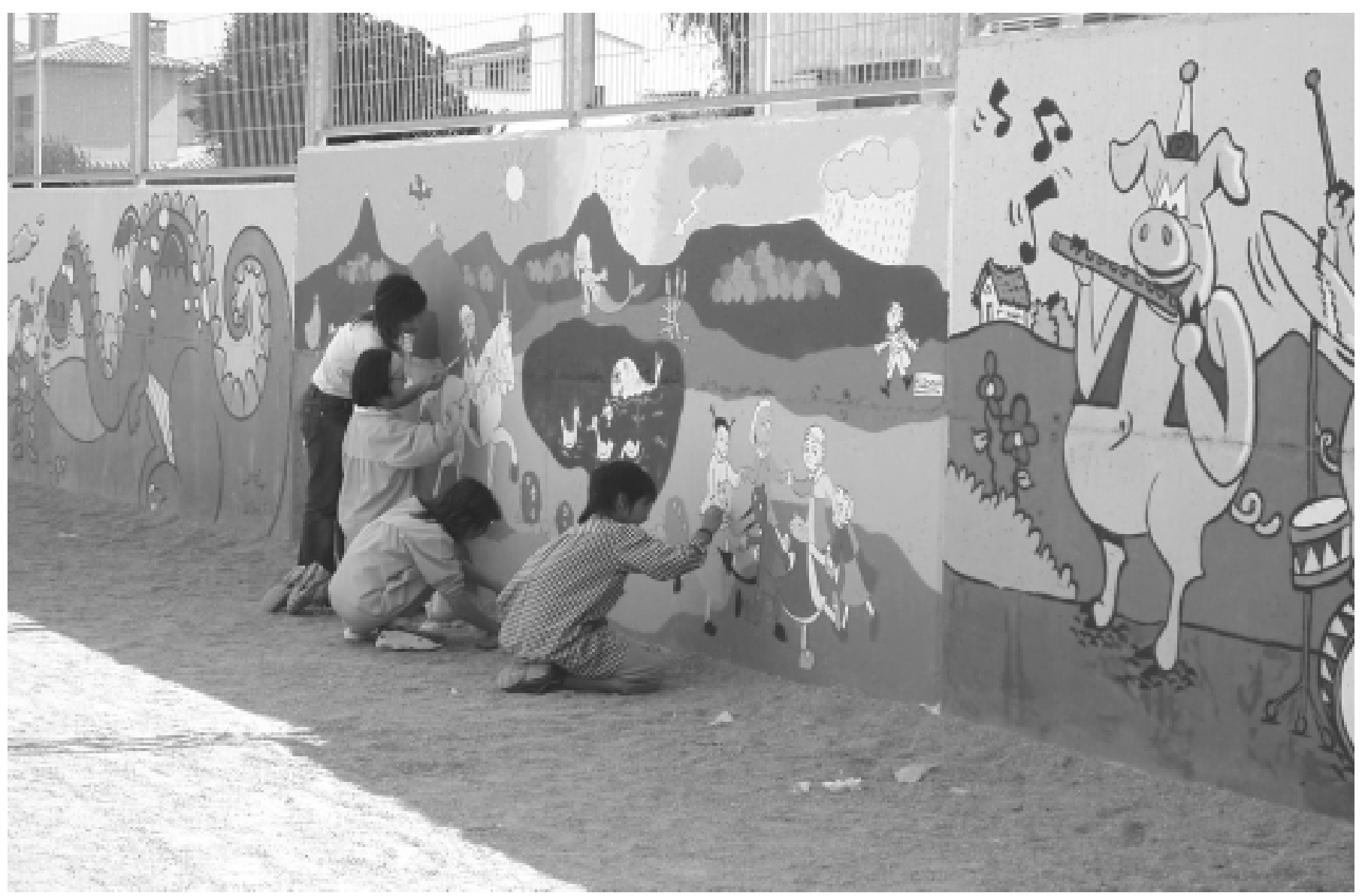

